\title{
Performance of Different Hollow Fiber Membranes for Seawater Desalination Using Membrane Distillation
}

\author{
Lijo Francis, Noreddine Ghaffour, Ahmad S. Al-Saadi, Gary Amy \\ Water Desalination and Reuse Center (WDRC), King Abdullah University of Science and \\ Technology (KAUST)
}

\begin{abstract}
Membrane Distillation (MD) requires a highly porous hydrophobic membrane with low surface energy. In this paper we compare the direct contact membrane distillation (DCMD) performances of four different types of in-house fabricated hollow fiber membranes and two different commercially available hollow fiber membranes. Hollow fiber membranes are fabricated using wet-jet phase inversion technique and the polymeric matrices used for the fabrication are poly vinylidine fluoride (PVDF) and poly vinyl chloride (PVC). Commercial hollow fiber membrane materials are made of poly tetra fluoro ethylene (PTFE) and poly propylene (PP). PVDF hollow fibers showed a superior performance among all the hollow fibers tested in the DCMD process and gave a water vapor flux of $31 \mathrm{~kg} \cdot \mathrm{m}^{-2} \mathrm{hr}^{-1}$ at a feed and coolant inlet temperatures of $80{ }^{\circ} \mathrm{C}$ and $20^{\circ} \mathrm{C}$, respectively. Under the same conditions the water vapor flux observed for PP, PTFE and PVC hollow fiber membranes are 13, 11 and $6 \mathrm{~kg} \cdot \mathrm{m}^{-2} \mathrm{hr}^{-1}$, respectively, with $99.99 \%$ salt rejection observed for all membranes used.
\end{abstract}

Keywords: Membrane technology; Hollow fiber membranes; Membrane fabrication; Water vapor flux; Partial vapor pressure. 


\section{Introduction}

Membrane Distillation (MD) is a membrane based thermal desalination process and considered as an attractive alternative technology for the fresh water reclamation either in desalination or wastewater treatment applications $[1,2]$. MD has the advantages of both conventional thermal desalination processes such as multi stage flash (MSF) and membrane based desalination technology such as reverse osmosis (RO). Conventional desalination technologies are energy intensive due to the use of high temperature, high pressure, expensive materials, large foot print and they are less environmentally friendly too. The MD process is attractive because it can utilize industrial low grade waste heat or renewable energy (e.g. solar, geothermal), less expensive membrane and module materials, less prone to fouling and scaling due to the high inertness of the membrane materials and lower operating pressures (ambient pressure), it offers high quality water production and all together MD is a low-cost desalination process and more environmentally friendly $[3,4]$.

The conventional MD configurations comprise direct contact membrane distillation (DCMD), air gap membrane distillation (AGMD), vacuum membrane distillation (VMD) and sweeping gas membrane distillation (SGMD) [5]. Permeate gap or liquid gap membrane distillation (PGMD/LGMD) [6] and material gap membrane distillation (MGMD) [7] are recently reported MD configurations. In all configurations hot feed solution is in direct contact with the membrane surface. In VMD and SGMD the condensation takes place outside the membrane module, whereas in all other configurations the water vapor from the feed solution pass through the membrane pores and condenses at the other side of the membrane inside the membrane module. 
Partial vapor pressure difference triggered by the temperature difference at the two sides of the membrane is the driving force in MD process and it allows only water papers to pass through the membrane pores and rejects all other salts and non-volatile compounds. Thus the MD process offers theoretically $100 \%$ salt rejection. High hydrophobicity, high porosity, minimum (optimum) thickness and high liquid entry pressure are the important requirements of a membrane to be successfully used for MD process [8-12]. Conventional membrane materials used for MD process are poly ethylene (PE), poly propylene (PP), poly vinylidine fluoride (PVDF) and poly tetra fluoro ethylene (PTFE). Some researchers have reported the modification of these materials to improve the MD performance [13-18]. Theoretical modeling, simulation and economic evaluation of the MD process have been also studied extensively to see whether the MD is economically viable or not [19-23]. Other studies have reported the synthesis and fabrication of fluorinated poly azole hollow fiber and nanofibers membranes for Seawater Membrane Distillation (SWMD) [24, 25]. Polymeric flat sheet MD membranes are fabricated using phase inversion, stretching and electrospinning techniques whereas hollow fiber membranes are fabricated using temperature induced phase separation (TIPS) and non-solvent induced phase separation (NIPS) techniques. Usually TIPS is employed for the materials that are not possible to form solutions at room temperature. In this paper different hollow fiber membranes (PVDF and PVC) are fabricated using NIPS technique and their DCMD performance was compared with that of commercially available PTFE and PP hydrophobic hollow fiber membranes. Results are also compared to the previously reported poly azole hollow fiber membranes.

\section{Experimental}


PVC (molecular weight $=250,000)$ and $\mathrm{N}$-methyl pyrrolidone $(\mathrm{NMP})$ were provided by Sigma Aldrich and PVDF is supplied by Arkema (Kynar HSV 900), PTFE and PP hollow fibers are supplied by different manufacturers and directly used for SWMD process without any modification. A hollow fiber machine (Samwon Engineering Co., Ltd., Korea) is employed for the fabrication of hollow fiber membranes. Figure 1 shows the hollow fiber machine and the schematic diagram of the hollow fiber fabrication.

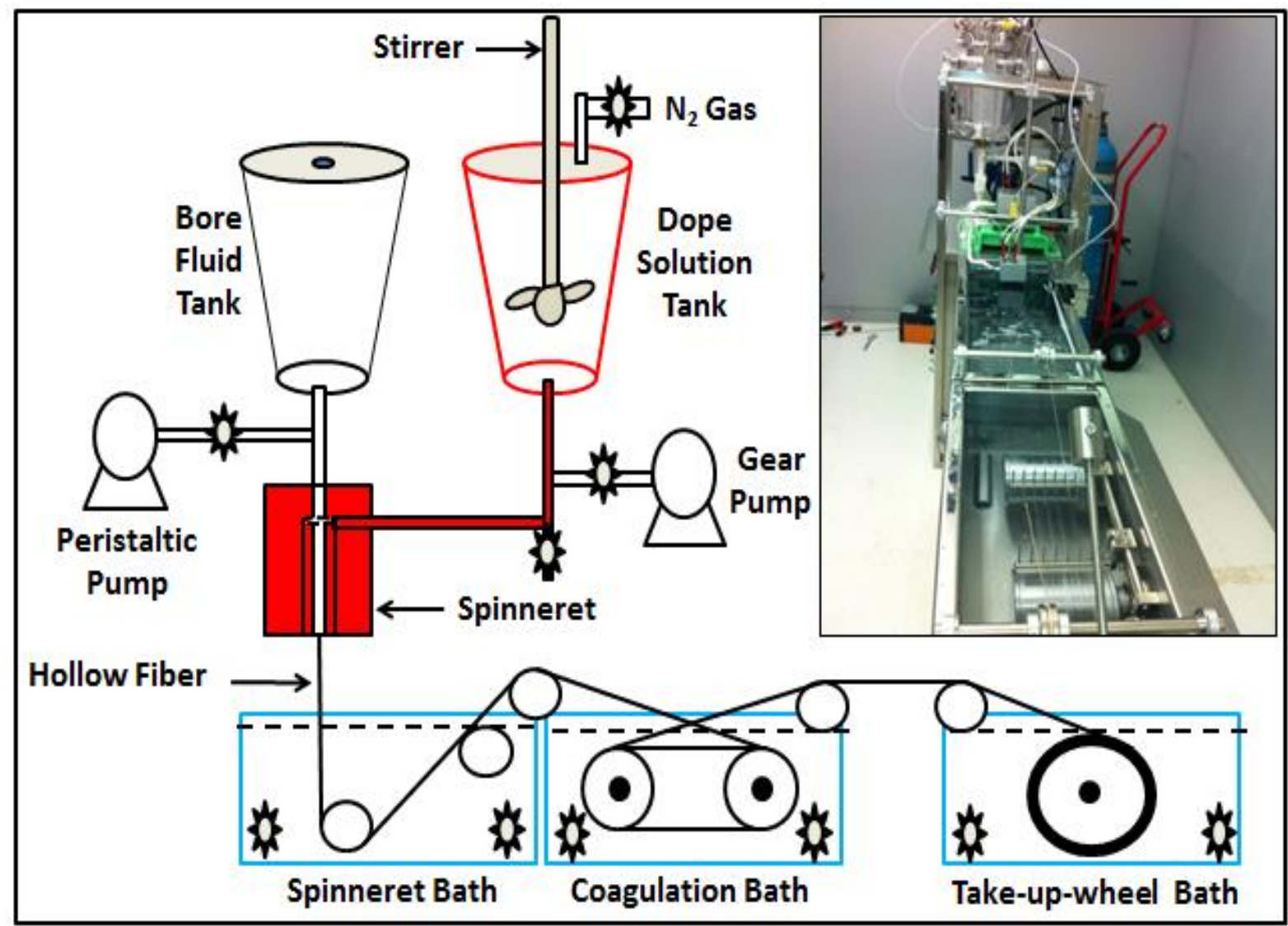

Figure 1. A schematic representation and machine of hollow fiber fabrication.

$12 \%(\mathrm{w} / \mathrm{w})$ solution of PVDF HSV 900 and $15 \%(\mathrm{w} / \mathrm{w})$ solution of PVC were prepared in NMP at $70{ }^{\circ} \mathrm{C}$. The polymeric solutions were degassed and fed into the annulus of the spinneret using a gear pump, whereas the tap water (bore fluid) was fed into the inner tube of the spinneret using a peristaltic pump. Phase separation of the dope solution starts from the outlet of the spinneret 
and fibers from the spinneret were allowed to pass through the spinneret bath, coagulant bath and take-up-wheel bath, as shown in the schematic presented in Figure 1. The distance between the spinneret and the spinneret bath was fixed at $5 \mathrm{~cm}$. The residual solvent from the raw fibers were removed by immersing them in a water bath for 3-5 days and freeze dried before characterization and MD process testing. Hollow fiber fabrication parameters are presented in Table 1.

Table 1. Fabrication conditions of PVDF and PVC hollow fibers

\begin{tabular}{ll}
\hline Dope solution & $12 \%(\mathrm{w} / \mathrm{w})$ PVDF HSV 900 in NMP and \\
& $15 \%(\mathrm{w} / \mathrm{w})$ PVC in NMP \\
Bore fluid \& External coagulant & Tap water \\
Air gap $(\mathrm{cm})$ & 5 \\
Bore fluid flow rate (mL min-1) & 10 \\
Gear pump rotation (rpm) & 15 \\
\hline
\end{tabular}

Membrane specimens were gold sputter coated using EMITECH K575 sputter coater and they were observed under field effect scanning electron microscope (FESEM Quanta 200 FEG Ltd). Hollow fiber membranes were glued together and inserted into the locally fabricated membrane modules and subjected to the DCMD process. Figure 2 shows the schematic representation of bench scale setup of the DCMD process. Feed solution (Red Sea water) was passed through the shell side of the membrane whereas the coolant (tap water) was passed through the lumen side of the membrane in a counter current direction. Temperatures at the coolant and feed sides were controlled using an electric chiller and an electric heater, respectively. During the MD process water vapor from the feed side pass through the membrane pores and condenses at the other side of the membrane along with the coolant. Water flux was calculated by recording the weight of permeate collected over time for a particular membrane 
area used for the MD process. Conductivity of the product permeate was measured using a conductivity meter (Oakton Eutech Instruments USA).

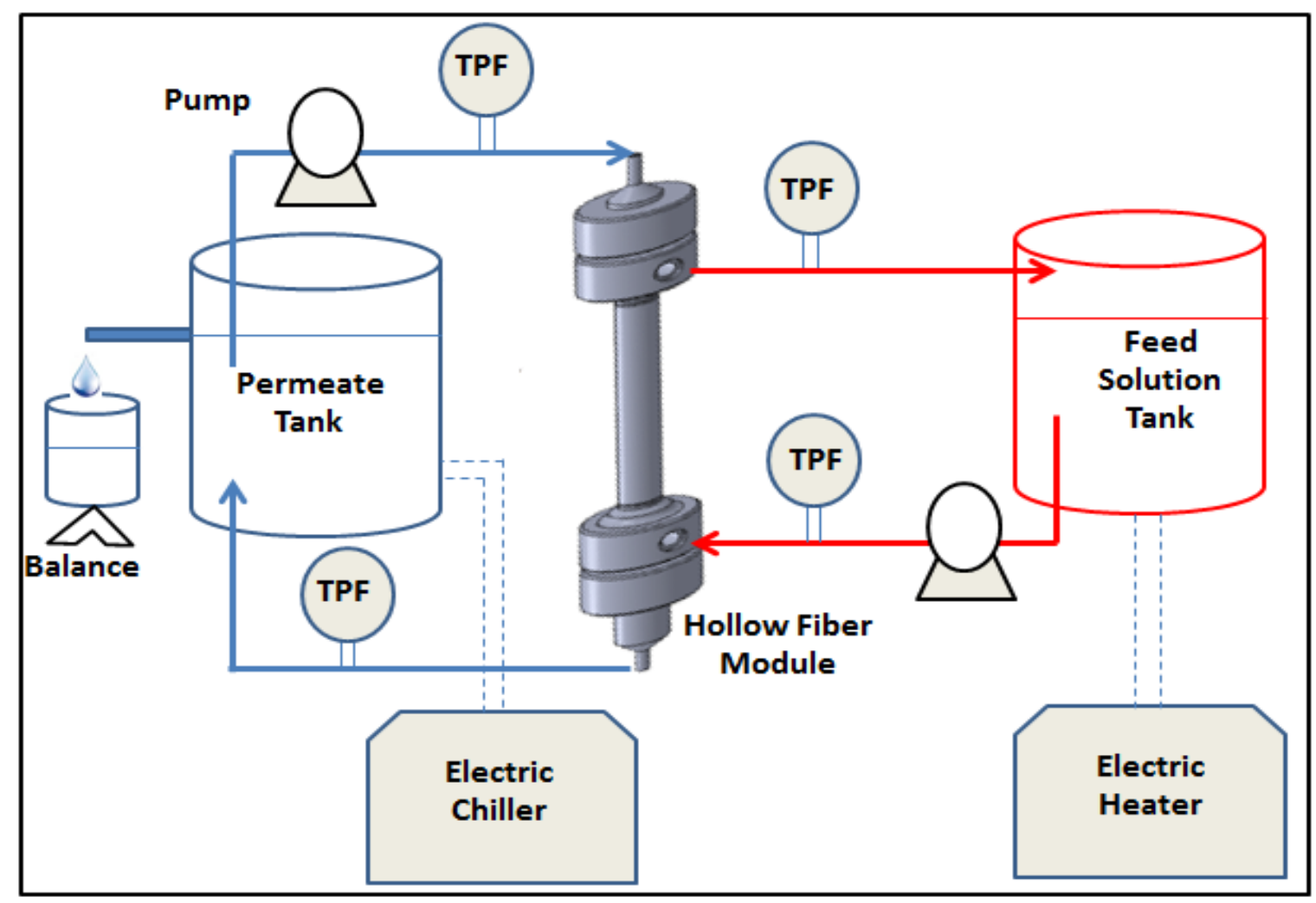

Figure 2. Schematic representation of bench scale set up of the DCMD process

\section{Results and Discussion}

Figure 3 shows the FESEM images of PVDF, PTFE, PP and PVC hollow fiber membranes. Cross sections show that the PVDF hollow fiber membrane is highly porous than all other membranes whereas the inner and outer surfaces of the membrane show that the PP membrane is highly porous than all other membranes. Surface porosity along with bulk porosity is very important in the MD process for the enhanced water vapor transport. Wall thickness of the PTFE membrane is about $500 \mu \mathrm{m}$ whereas the thicknesses of all other membranes are calculated to be in the range of 200-250 $\mu \mathrm{m}$. Increase in the thickness results in increased mass and heat transfer 
resistances and decrease in the water production. Outer surface of PTFE membrane reveals crack type morphology whereas that of PVC membrane reveals a dense surface.

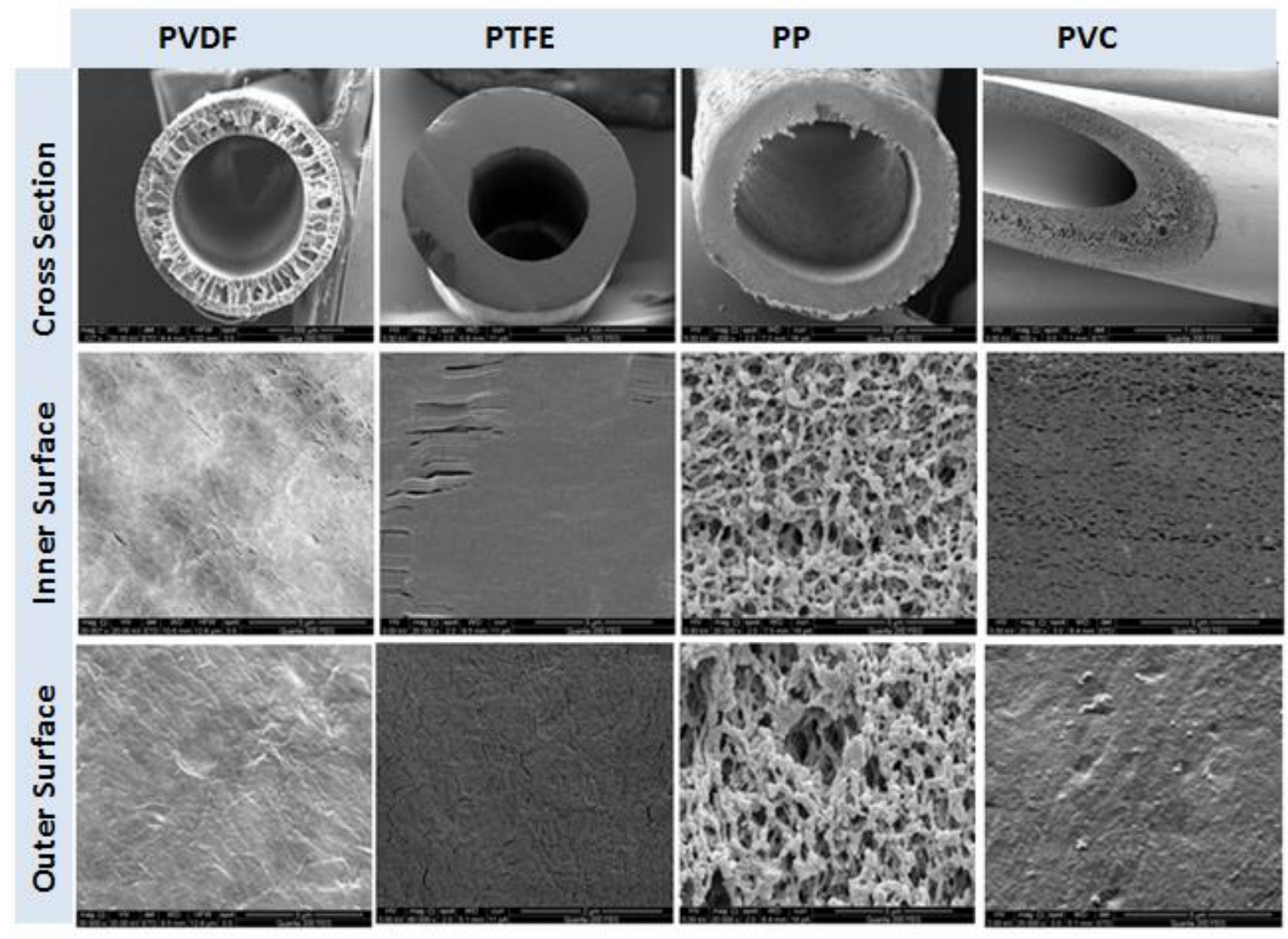

Figure 3. FESEM images of hollow fiber membranes.

Figure 4 shows the DCMD water vapor flux comparison of different hollow fiber membranes used in this study. The results are obtained by using a coolant temperature of $20{ }^{\circ} \mathrm{C}$ and feed solution temperature varying from $40-80{ }^{\circ} \mathrm{C}$. Partial vapor pressure is higher at higher feed temperatures and trans-membrane pressure increases as the temperature difference at the two sides of the membrane increases. This results in the increase in the water flux at higher feed solution temperatures at constant coolant temperature. As shown from the SEM images PVDF hollow fiber membranes gave the highest water vapor flux of $31 \mathrm{~kg} \mathrm{~m}^{-2} \mathrm{~h}^{-1}$ compared to other 
membranes under similar operating conditions. PP hollow fiber membrane surface is highly porous but from the cross section image, the bulk porosity might be very less and leads to the increased mass transfer resistance and reduced flux during the DCMD process. SEM images also show that the PTFE hollow fiber membrane is not only less porous but also thicker among the other membranes used in this study. Heat and mass transfer resistance will be very high in such conditions and lead to low flux.

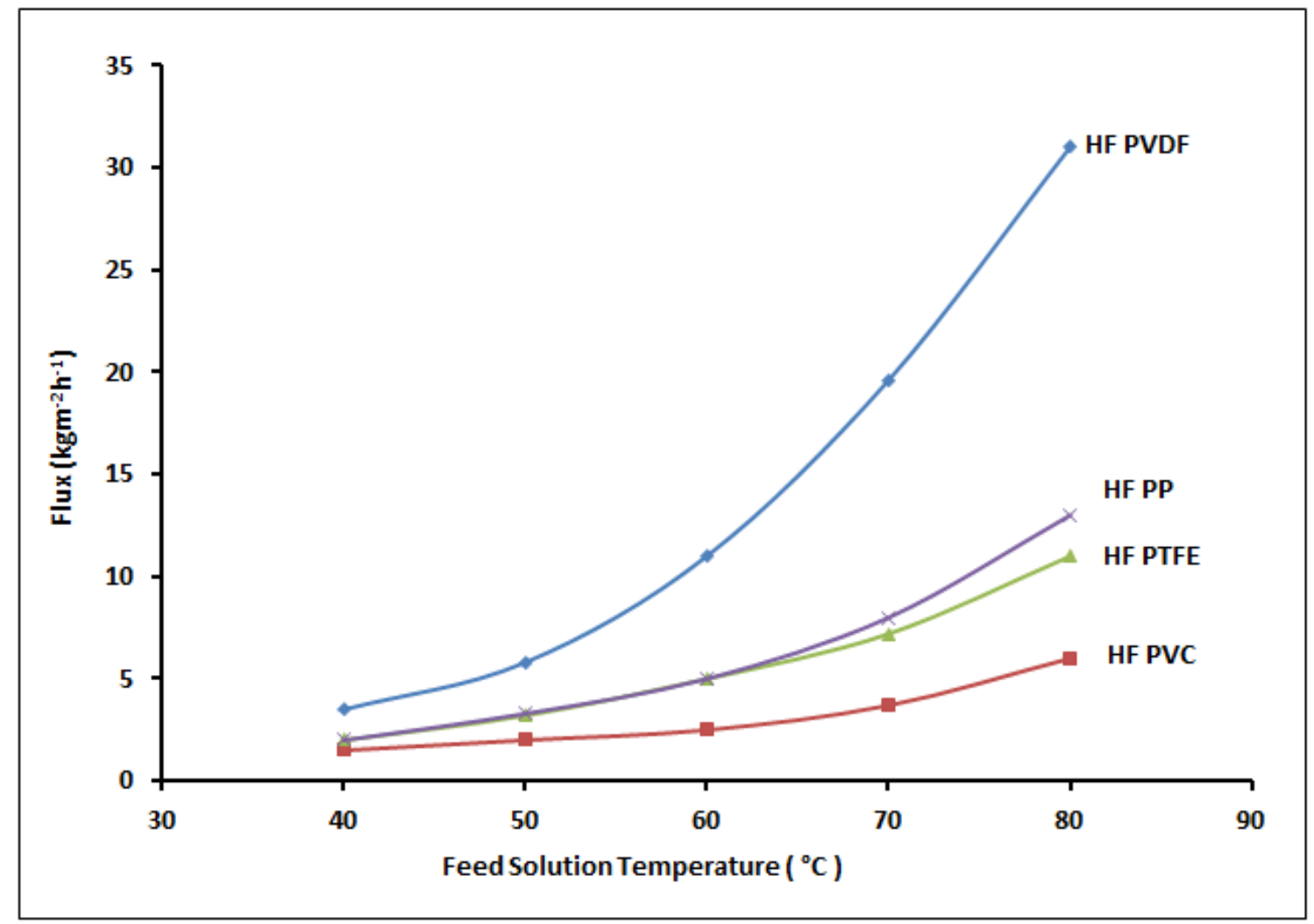

Figure 4. DCMD water vapor flux against feed solution temperature for different hollow fiber membranes. Coolant temperature $=20^{\circ} \mathrm{C}$, feed $/$ coolant flow rates $=1 \mathrm{LPM}$.

Figure 5 shows that the DCMD water vapor fluxes obtained for different hollow fiber membranes at different coolant temperatures $\left(10,20\right.$ and $\left.30^{\circ} \mathrm{C}\right)$ and at a constant feed solution temperature of $60{ }^{\circ} \mathrm{C}$ and constant feed/coolant flow rates of 1 LPM. As reported in previous studies $[26,27]$, water vapor pressure at low temperatures is significantly lower than that at 
higher temperatures resulting in lower water flux at constant feed solution temperature. For PVDF hollow fiber membranes water flux observed at a feed/coolant temperature of $60 / 20{ }^{\circ} \mathrm{C}$ was $11 \mathrm{~kg} \mathrm{~m}^{-2} \mathrm{~h}^{-1}$. When the coolant temperature is decreased from 20 to $10^{\circ} \mathrm{C}$, the water flux was found to be increased by $4 \%$ only. While for the same hollow fiber membranes when the feed solution temperature is increased from 60 to $70{ }^{\circ} \mathrm{C}$, the water flux was increased by $78 \%$.

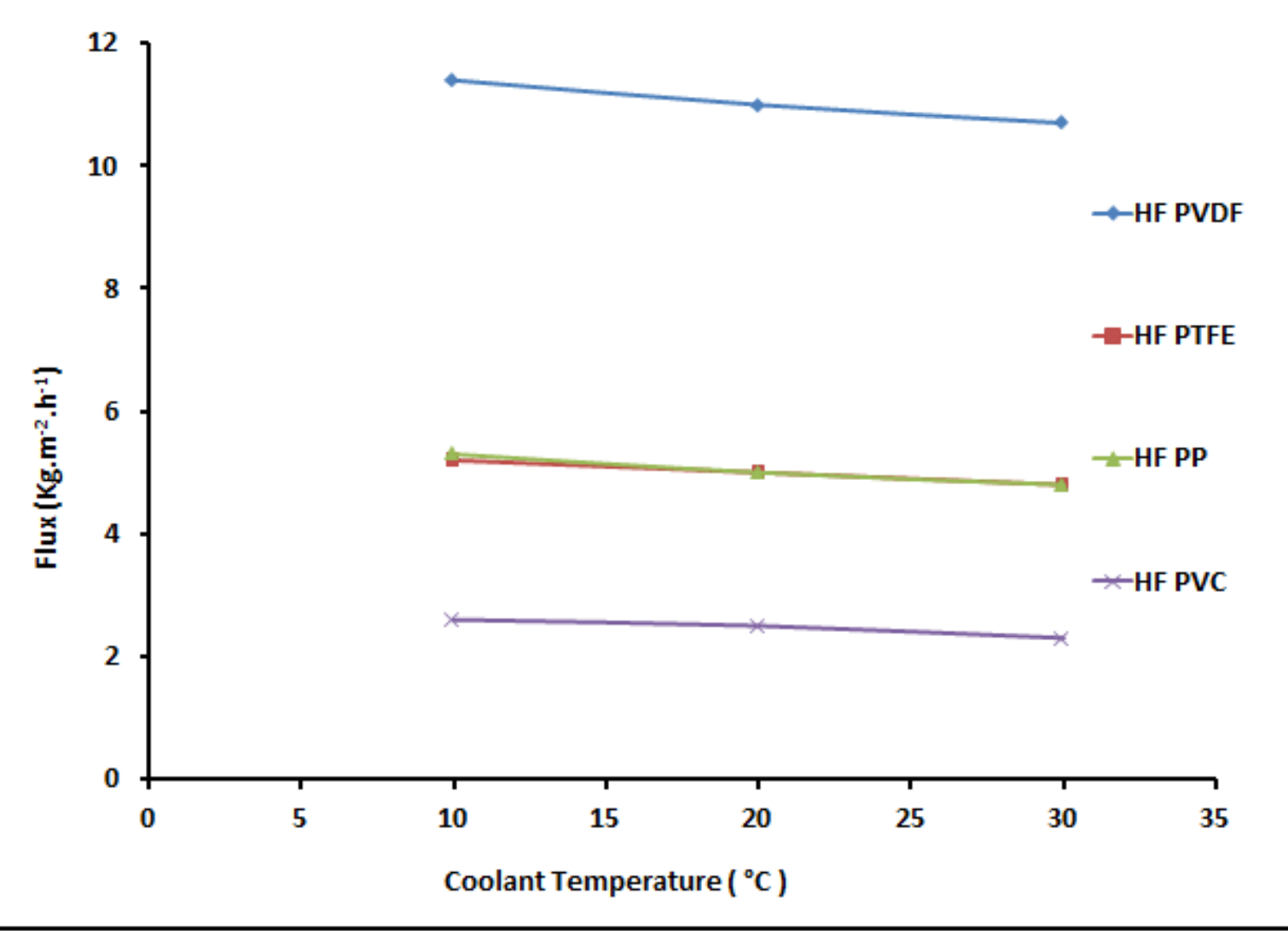

Figure 5. DCMD water vapor flux against feed solution temperature for different hollow fiber membranes. Feed temperature $=60{ }^{\circ} \mathrm{C}$, feed $/$ coolant flow rates $=1 \mathrm{LPM}$.

In the present study PVDF hollow fiber membranes showed superior performance to the other membranes, however high performance membranes are yet to be developed for better water recovery enabling to supply high quality water at low cost. It was reported in our previous work that the locally synthesized and fabricated poly azole hollow fiber membranes gave water vapor fluxes of 35 and $41 \mathrm{~kg} \mathrm{~m}^{-2} \mathrm{~h}^{-1}$ under similar operating conditions [25]. Hollow fiber membranes 
are advantageous over flat sheet membranes in terms of self-support and packing density. Along with these merits, high flux membranes are yet to be engineered in terms of large scale production and long term performance with low fouling and scaling index.

\section{Conclusions}

PVDF, PP, PTFE and PVC hollow fiber membranes are fabricated and their SWMD performances using DCMD configuration have been evaluated. PVDF hollow fiber membrane showed the highest water vapor flux of $31 \mathrm{~kg} \mathrm{~m}^{-2} \mathrm{~h}^{-1}$ whereas the second highest flux observed with PP hollow fiber membrane is $13 \mathrm{~kg} \mathrm{~m}^{-2} \mathrm{~h}^{-1}$. Rate of change of water vapor flux by varying $\Delta \mathrm{T}$ at the coolant side is negligible when compared to the similar change of $\Delta \mathrm{T}$ at feed solution temperatures. Better membranes are yet to be engineered and developed for better water recovery enable to supply high quality water at low cost.

\section{References}

[1] A.G. Fane, R.W. Schofield, C.J.D. Fell, The Efficient Use of Energy in Membrane Distillation, Desalination 64 (1987) 231-243.

[2] G.C. Sarti, C. Gostoli, S. Matulli, Low energy cost desalination processes using hydrophobic membranes, Desalination, 56 (1985) 277-286.

[3] L. Camacho, L. Dumée, J. Zhang, J.-d. Li, M. Duke, J. Gomez, S. Gray, Advances in Membrane Distillation for Water Desalination and Purification Applications, Water 5 (2013) 94-196.

[4] J.H. Hanemaaijer, Memstill@ — low cost membrane distillation technology for seawater desalination, Desalination 168 (2004) 355.

[5] M. Khayet, T. Matsuura, Membrane distillation: principles and applications, Access Online via Elsevier, 2011.

[6] A.Cipollina, M.G. DiSparti, A. Tamburini, G. Micale, Development of a membrane Distillation module for solar energy seawater desalination, Chem Eng Res Des 90(12) (2012) 2101-2121. 
[7] L. Francis, N. Ghaffour, A.A. Alsaadi, G.L. Amy, Material gap membrane distillation: A new design for water vapor flux enhancement. J. Membr. Sci. 448 (2013) 240-247.

[8] L. Francis, A.S. Alsaadi, N. Ghaffour, G.L. Amy, Performance evaluation of the DCMD desalination process under bench scale and large scale module operating conditions, J. Membr. Sci. 455 (2014) 103-112.

[9] A. Alkhudhiri, N. Darwish, Nidal Hilal, Membrane distillation : A comprehensive review. Desalination 287 (2012) 2-18.

[10] M.S. El-Bourawi, Z. Ding, R. Ma, M. Khayat, A framework for better understanding membrane distillation separation process, J. Membr. Sci. 285 (1-2) (2006) 4-29.

[11] N. Peng, N. Widjojo, P. Sukitpaneenit, M.M. Teoh, G.G. Lipscomb, T.S. Chung, J.Y. Lai, Evolution of polymeric hollow fibers as sustainable technologies: past, present and future, Prog. Polym. Sci. 37 (2012) 1401-1424.

[12] P.Wang, T.S. Chung, Design and fabrication of lotus-root-like multi-bore hollow fiber membrane for direct contact membrane distillation, J. Membr. Sci. 421-422 (2012) 361-374.

[13] L. Shi, R. Wang, Y. Cao, C. Feng, D.T. Liang, J.H. Tay, Fabrication of poly(vinylidine fluoride-co-hexafluropylene) (PVDF-HFP) asymmetric microporous hollow fiber membranes, J. Membr. Sci. 305 (1-2) (2007) 215-225.

[14] Dumée, L.; Germain, V.; Sears, K.; Schütz, J.; Finn, N.; Duke, M.; Cerneaux, S.; Cornu, D.; Gray, S. Enhanced durability and hydrophobicity of carbon nanotube bucky paper membranes in membrane distillation. J. Membr. Sci. 2011, 376, 241-246.

[15] García-Payo, M.C.; Essalhi, M.; Khayet, M. Preparation and characterization of PVDF-HFP copolymer hollow fiber membranes for membrane distillation. Desalination 2009, 245, 469-473.

[16] Qtaishat, M.; Khayet, M.; Matsuura, T. Novel porous composite hydrophobic/ hydrophilic polysulfone membranes for desalination by direct contact membrane distillation. J. Membr. Sci.2009, 341, 139-148.

[17] Edwie, F.; Teoh, M.M.; Chung, T.-S. Effects of additives on dual-layer hydrophobichydrophilic pvdf hollow fiber membranes for membrane distillation and continuous performance. Chem. Eng.Sci. 2012, 68, 567-578. 
[18] Boor Singh Lalia Elena Guillen Hassan A. Arafat Raed Hashaikeh, Nanocrystalline cellulose reinforced PVDF-HFP membranes for membrane distillation application, Desalination 332 (2014) 134-141.

[19] ] A.S. Alsaadi, A.S, N. Ghaffour, J.D. Li, S. Gray, L. Francis, H. Maab, G.L. Amy, Modeling of air-gap membrane distillation process: A theoretical and experimental study, J. Membr. Sci. 445 (2013) 53-65.

[20] Rasha B. Saffarini, Edward K. Summers, Hassan A. Arafat, John H. Lienhard, Economic evaluation of stand-alone solar powered membrane distillation systems, Desalination, 299 (2012) 55-62.

[21] Y.D.Kim, K.Thu, N.Ghaffour, K.C.Ng, Along-term performance investigation of solar-assisted hollow fiber DCMD desalination system, J.Memb.Sci.427 (2013) 345-364.

[22] F.Banat, N.Jwaied, Economic evaluation of desalination by small-scale autonomous solarpowered membrane distillation units, Desalination, 220 (2008) 566-573.

[23] G. Zuo, R. Wang, R. Field, A.G. Fane, Energy efficiency evaluation and economic analyses of direct contact membrane distillation system using Aspen Plus Desalination, 283 (2011) 237-244.

[24] H. Maab, L. Francis, A.S. Alsaadi, C. Aubry, N. Ghaffour, G.L. Amy, S.P. Nunes, Synthesis and fabrication of nanostructured hydrophobic polyazole membranes for low-energy water recovery, J. Membr. Sci. 423-424 (2012) 11-19.

[25] H. Maab, A. Alsaadi, L. Francis, S. Livazovic, N. Ghaffour, G.L. Amy, S.P. Nunes, Polyazole hollow fiber membranes for direct contact membrane distillation, Industrial \& Engineering Chemistry Research 52 (2013) 10425-10429.

[26] L. Francis, N. Ghaffour, A. AlSaadi, S. Nunes, G. Amy, PVDF hollow fiber and nanofibers membranes for fresh water reclamation using membrane distillation, J Mater Sci 49 (2014) 2045-2053.

[27] L. Francis, H. Maab, A. AlSaadi, S. Nunes, N. Ghaffour, G.L. AmyGL, Fabrication of electrospun nanofibrous membranes for membrane distillation application, Desalin.Water. Treat. 51(7-9) (2013) 1337-1343. 